\title{
PENGARUH METODE RESITASI TERHADAP PRESTASI HASIL BELAJAR PENDIDIKAN ASWAJA NAHDLATUL ULAMA
}

\author{
Universitas Yudharta Pasuruan, East Java, Indonesia \\ Denis Saputra dan Ahmad Ma'ruf \\ denis.saputra1998@gmail.com, ahmad.maruf@yudharta.ac.id
}

\begin{abstract}
Absract: This thesis discusses the influence of the method of recitation of education learning outcomes Aswaja Nahdlatul Ulama class IV Madrasah Diniyah Ketuwon Sumberrejo. This study was backed by the problems in the process of teaching and learning activities, how to send the material to learners optimally and effectively so as to create an interactive educative between educators and learners. The lack of interest of teachers in the variation of use of teaching methods makes learners feel saturated in the process of learning to teach, the result of quality improvement efforts is not running optimally and effectively. This research is experimental ASN experiments. This research aims to determine the influence of the method of recitation on the achievement of education Outcomes Aswaja Nahdlatul Ulama class IV Madrasah Diniyah Shobibur Rohmat Ketuwon Sumberrejo. This research uses a quantitative approach with the type of experiment. Variables in this study are free variables in the form of students of grade IV Madrasah Diniyah Shobibur Rohmat and the variables are tied in the form of student learning outcomes, the subject of this study is all students of grade IV Madrasah Diniyah Shobibur Rohmat amounted to 19 students and samples in the study took all class IV students Madrasah Diniyah Shobibur Rohmat which amounted to The technique of data collection in this research is the double choice test in the form of pretests and posttest. Testing of hypotheses requirements using test (Independent Sample T-Test). The results are known that there is a difference between the results of learning using the method of resitation with conventional methods, the value of studying students using conventional methods of 63.42 and after using the method of Resitation of 76.05. Differences in learning outcomes use a resitation method of $19 \%$. The inconclusive method of resitation can affect the achievement of student learning outcomes, analysis of student test results in tests using t test with the acquisition of $T$ 8.715.
\end{abstract}

Keywords: Influence, Method Of Resitation, Achievement Of Learning Outcomes

\section{A. Pendahuluan}

Pendidikan merupakan pondasi utama bagi masyarakan di seluruh dunia, dengan pendidikan manusia bisa melakukan hal-hal yang luar biasa. Tanpa adanya pendidikan manusia kosong akan keilmuan dan 
sama seperti halnya hewan. Karena pada dasarnya manusia diberikan akal oleh Allah SWT, untuk memahami segala sesuatu apa yang bisa di indera oleh manusia. Dengan pendidikan manusia dapat mengembangkan potensi yang ada dalam dirinya, baik itu dalam hal kecerdasan, keahlian ataupun yang lainnya. Pendidikan juga sebagai kekuatan untuk membantu manusia mencapai kemegahan dan kemajuan peradaban. Tidak hanya itu pembelajaran pula membagikan bekal untuk manusia buat menyambut hari besok yang lebih terang serta lebih manusiawi. Pembelajaran salah satu faktor yang sangat berarti serta aktual sejauh masa, sebab dengan pembelajaran manusia hendak mendapatkan pengetahuan serta keahlian dalam mengelolah alam yang dikaruniakan Allah SWT kepada kita. Pendidikan berkontribusi besar baik itu dalam pembinaan moral, pensejahteraan dan bahkan membawa kemajuan bagi suatu dirinya atau bahkan negaranya. Dalam proses membangun dan mencerdaskan anak bangsa pendidikan sangat berperan aktif, khususnya di sekolah-sekolah, dimana disitulah proses belajar mengajar dan evaluasi pendidikan berlangsung. Proses aktivitas belajar mengajar yang diterapkan di sekolah maupun di dalam kehidupan tiap hari pasti saja mengaitkan proses kognitif. Proses kognitif sendiri meliputi proses belajar, memahami, mengingat serta persepsi. Pada masing-masing individu memiliki kemampuan kognitif yang berbeda-beda, yang semuanya tergantung pada bagaimana mereka dalam menggunakan dan bagaimana dia melatihnya. Hambatan dalam dunia pembelajaran dikala ini biasanya terletak pada kesusahan para siswa dalam menangkap data, baik itu dalam menguasai ataupun mengingat kembali apa yang telah dipelajari di sekolah. $^{2}$

Pada kenyataannya masih banyak pendidik yang tidak peduli dengan penggunaan metode pembelajaran yang dapat mempermudah siswa dalam menangkap pelajaran, di era ini sangatlah dibutuhkan tenaga pendidik yang kreatif yang dapat menyumbangkan bermakna pada ilmu pengetahuan teknologi dan kesenian, serta pada kesejahteraan bangsa pada umumnya tanpa meninggalkan nilai-nilai keislaman. Berhubungan dengan itu pembelajaran sebaiknya tertuju pada pengembangan kreativitas partisipan didik supaya nanti bisa penuhi kebutuhan individu, kebutuhan warga serta negeri. ${ }^{3}$ Maka dari itu perlu kesadaran dari para pendidik untuk memikirkannya anak didiknya, bagaimana mereka dapat menangkap materi dengan mudah dapat mengingatnya kembali. Salah satu cara yang dapat digunakkan yaitu metode pembelajaran. Dengan pemilihan metode pembelajaran yang sesuai dengan materi dan anak didik maka proses pembelajaran akan berlangsung secara efisien.

\footnotetext{
${ }^{1}$ Untari Retno Wulan, Skripsi, "efektivitas brain gyn dalam meningkatkan daya ingat jangka pendek pada anak" (Universitas muhammadiyah surakarta, 2010), 1.

2 Untari Retno Wulan, Skripsi, "efektivitas brain gyn," 3.

${ }^{3}$ Fuat agus santoso, Skripsi, "kreativitas belajarsiswa ditinjau dari lingkungan keluarga dan fasilitas belajar pada siswa kelas VIII SMP N 1 Kartasura tahun ajaran 2013/2014", (universitas muhammadiyah surakarta, 2014), 3.
} 
Metode sendiri adalah salah satu penentu keberhasilan dalam proses pembelajaran. Metode pengajaran adalah suatu cara untuk menyajikan pesan pembelajaran, sehingga pencapaian hasil belajar dapat optimal. Tanpa metode, suatu pesan pembelajaran tidak akan dapat berproses secara efektif dalam kegiatan belajar mengajar ke arah yang dicapai. ${ }^{4}$ Strategi pengajaran yang tidak tepat bakal jadi penghalang kelancaran jalannya proses belajar mengajar. Oleh sebab itu tata cara yang diresmikan seseorang guru akan menemukan hasil yang maksimal, bila sanggup dipergunakan untuk menggapai tujuan yang ditetapkan. Terdapat peserta didik yang lebih suka membaca, dialog ataupun praktek langsung. Supaya bisa menopang peserta didik belajar secara optimal, kesenangan dalam belajar itu butuh dicermati. Salah satunya dengan menggunakan variasi metode pembelajaran yang beragam dengan melibatkan indera belajar yang banyak, karena siswa akan lebih cepat memahami pelajaran apabila siswa dilibatkan secara aktif baik mental maupun fisik.

Salah satu permasalahan yang kritis yakni bagaimana bisa menciptakan serta mengidentifikasi kemampuan kreatif siswa serta bagaimana bisa mengembangkannya lewat pengalaman pembelajaran dalam arti tingkatkan keahlian membaca. Kreativitas itu semacam halnya kemampuan lain, ialah butuh diberi peluang serta rangsangan oleh lingkungan untuk tumbuh. ${ }^{5}$

Pembelajaran tidak lepas dari masalah- masalah yang ada, baik dari segi pengelolaan, kurikulum, guru, siswa serta lain- lain. Masalah pendidikan merupakan masalah sepanjang sejarah manusia, dan melalui pendidikan pula manusia membangun kebudayaan serta peradaban yang ada sampai saat ini. Proses pendidikan dapat dilakukan dengan belajar disekolah formal yang terlembagakan atau pun pendidikan nonformal meskipun sejatinya belajar dapat dilakukan dimana saja termasuk dalam keluarga. $^{6}$ Salah satu masalah yang sering dihadapi guru adalah pengelolaan kelas, tentang model, strategi ataupun metode pembelajaran

${ }^{4}$ Zulkifli, Skripsi, "Meningkatkan Hasil Belajar Siswa Pada Mata Pelajaran Akidah Akhlak Kelas Viii-A Pokok Bahasan Beriman Kepada Kitab Allah Dengan Penerapan Strategi Index Card Match Di Madrasah Tsanawiyah Swasta Nurul Wathan Tahun Ajaran 2013/2014”, ( Institut Agama Islam Darul Al-Ulum, 2014), 3.

${ }^{5}$ Rizka Ramadhanti, Skripsi, "Upaya Meningkatkan Hasil Belajar Siswadengan Mengunakan Metode Inquiri Learning Pada Mata Pelajaran Alqur'an Hadits Materi Hukum Bacaan Idgham Bighunnah,Idgham Bilaghunna Dan Ikhfa Di Kelas VIII Di Mts Al-Ikhlas Pangkalan Susu", (Sekolah Tinggi Agama Islam Jam'iyah Mahmudiyah Tanjung Puralangkat, 2018), 4.

${ }^{6}$ Romi Anshorulloh, Skripsi, "Efektivitas Metode Mnemonika Dalam Meningkatkan Daya Ingat Siswa Dalam Pelajaran Sejarah di MTS Persiapan Negeri Kota Batu" (Universitas Islam Negeri Malang, 2008), 14. 
yang mereka gunakan. Dalam proses pendidikan di kelas, tiap guru berperan selaku pengajar serta pembimbing, harus melaksanakan layanan tutorial belajar baik secara kelompok ataupun secara individual. Hal ini dimaksudkan agar hasil belajar yang dicapai siswa dapat memenuhi kreteria pencapaian tujuan instruksional yang diharapkan oleh setiap guru pastinya. Pada umumnya pembelajaran masih belum memperoleh hasil yang maksimal, misalnya pasti ada beberapa siswa yang sulit memahami materi. Hal tersebut dikarenakan dalam proses pembelajaran siswa kurang berperan aktif sedangkan guru masih banyak yang menggunakan metode yang lumrah. ${ }^{7}$ Kunci keberhasilan pembelajaran ada pada seorang guru, tetapi bukan berarti dalam proses pembelajaran hanya guru yang aktif. Keahlian guru dalam mengajar banyak mempengaruhi terhadap keberhasilan pencapaian tujuan pembelajaran, maksudnya keterlibatan guru secara langsung dalam proses belajar mengajar sangat memastikan keberhasilan proses pembelajaran. Oleh karena itu guru bagaikan tenaga pendidik butuh menguasai tentang strategi pendidikan ialah tata cara yang bisa digunakan dalam proses belajar mengajar. Tidak hanya guru pendidikan formal saja yang harus mengetahui strategi pembelajaran atau pun metode yang digunakan, sebagai guru nonformal juga penting untuk mengetahui strategi mengajar yang mudah diterima oleh peserta didik dengan menggunakan metode yang sesuai dengan materi yang disampaikan.

Penerapan metode pembelajaran yang kurang tepat saat mengajar, seringkali siswa sulit untuk mengingat kembali tentang materi atau pelajaran yang telah di berikan oleh guru, kebanyakan guru sering memberikan pelajaran dengan metode pembelajaran ceramah. Dalam menyajikan materi pelajaran dapat digunakan sebuah pendekatan dan metode yang dapat memudahkan peserta didik dalam belajar, serta dapat dengan mudah di ingat-ingat oleh peserta didik. Hal yang perlu diperhatikan dalam usaha meningkatkan kualitas pendidikan yaitu bagaimana cara mengemas penyelenggaraan proses pembelajaran yang mudah dipahami oleh murid, guru sebagai pelaksana pendidikan yang menjadi peran utama dalam menentukan keberhasilan proses pembelajaran selain faktor-faktor lain yang mempengaruhi proses pembelajaran seperti peserta didik, bahan ajar, motivasi, dan sarana prasarana yang menjadi penunjang keberhasilan proses pendidikan. Maka dari itu inovasi dan kreasi guru sangat menentukan keberhasilan pendidikan dalam meningkatkan kualitas pendidikan. Pendidikan nonformal juga tak lepas dari permasalah-permasalan tersebut, dalam pendidikan nonformal misalnya Madrasah Diniyah juga perlu adanya inovasi dan kreasi baru yang perlu diterapkan oleh guru, selama ini guru

\footnotetext{
7 Rosniah, Skripsi, "Meningkatkan daya ingat siswa dalam menghafal Asmaul husna melalui strategi index card Match pada siswa kelas II sekolah dasar Negeri 013 teluk air karimun" (Universitas Islam Negeri Sultan Syarif Kasim Riau, 2013), 1.
} 
pendidikaan nonformal kebanyakan meremehkan metode atau cara menyampaikan materi, mereka hanya menggunakan metode ceramah yang kemungkinan besar para siswa akan bosan dan jenuh dengan kegiatan belajar mengajar. Seperti halnya pada pelajaran Pendidikan Ahlusunnah Waljama'ah (Aswaja) dan Nahdlatul Ulama di Madrasah Diniyah, mata pelajaran ini membahas tentang sejarah nahdlatul ulama, yang kebanyakan guru hanya menggunakan metode ceramah. ${ }^{8}$

Banyak hal yang bisa dilakukan oleh seorang guru untuk menciptakan metode pembelajaran yang dapat meningkatkan kreatifitas dan mengukur hasil belajar siswa dalam kegiatan belajar mengajar dalam kelas. Seperti halnya pemberian tugas, dalam pemberian tugas guru dapat melihat seberapa jauh daya ingat siswa dengan pembelajaran yang telah disampaikan guru dan tugas tersebut juga bisa dijadikan sebagai acuan untuk menilai kemampuan siswa. Pemberian tugas kepada siswa bukanlah hal yang baru, akan tetapi penerapanya yang kurang maksimal, kebanyakan guru memberikan tugas hanya sebagai kesibukan siswa dalam belajar dikelas dan selanjutnya tugas tersebut dikumpulkan tanpa adanya tindak lanjut dari guru setelah pemberian tugas tersebut sehingga tugas tersebut terabaikan sebagai acuan guru dalam menilai siswa.

Mengingat pentingnya partisipasi siswa dalam proses pembelajaran, sebagai seorang guru dapat menciptakan suasana pembelajaran yang melibatkan keaktifan siswa misalnya dalam pembelajaran Aswaja, Aswaja adalah faham keislaman yang berpegang pada ajaran Nabi Muhammad SAW dan pentunjuk para sahabat. ${ }^{9}$ Ahlus Sunnah Wal Jama"ah (Aswaja) adalah suatu golongan mayoritas kaum muslimin yang mengklaim sebagai pengikut Nabi SAW dan menerima konsensus (ijma') para sahabat. ${ }^{10}$ Pembelajaran Aswaja bisa dibilang memuat materi pembelajaran yang cukup banyak, sedangkan pembelajaran di madrasah diniyah tidak memiliki waktu yang panjang seperti di lembaga formal, maka peneliti ingin menerapkan metode resitasi yang memberikan kesempatan kepada peserta didik untuk berpartisipasi dalam proses pembelajaran serta dapat meningkatkan motivasi hasil belajar siswa. Metode resitasi adalah metode penyajian bahan ajar dengan cara guru memberikan tugas kepada peserta didik dengan harapan peserta didik melakukan kegiatan belajar. Tugas yang diberikan oleh guru dapat dikerjakan dimanapun seperti didalam kelas, perpustakaan, rumah ataupun tempat lainnya. Metode ini dapat diterapkan sebagai jalan pintas untuk mempelajari materi dengan

8Sholih Muhammad, Muhammad Farid dan Abdul Karim, Pendidikan Aswaja dan Nabdlatul Ulama, (Ma'hadud Tarbiyah wa ta'lim Maarif nahdlatul ulama kabupaten pasuruan, 2014), 2.

${ }^{9}$ Muhammad Sholih, Muhammad Farid dan Abdul Karim, Pendidikan Aswaja dan Nahdlatul Ulama (Ma'hadud Tarbiyah wa ta'lim Maarif nahdlatul ulama kabupaten pasuruan, 2014), 1.

${ }^{10}$ Siti Choriyah, Skripsi, "Implementasi Pembelajaran Aswaja Untuk Peningkatan Iman Dan Taqwadi Smk Al Falahsalatiga" (Institut Agama Islam Negeri (iain) Salatiga, 2018), 17. 
bobot yang cukup banyak sedangkan waktu yang diberikan cukup singkat. ${ }^{11}$

Selain itu, peneliti juga ingin mengetahui seberapa pengaruh metode resitasi terhadap hasil belajar siswa yang akan diteliti. Dalam hal ini peneliti mengakat judul "Pengaruh Metode Resitasi Terhadap Prestasi Hasil Belajar Pendidikan Aswaja Nahdlatul Ulama Kelas IV di Madrasah Diniyah Shobibur Rohmat Ketuwon Sumberrejo".

\section{B. Kajian Teori}

a. Penngertian metode resitasi

Metode resitasi adalah metode penyajian bahan ajar dengan cara guru memberikan tugas kepada peserta didik dengan harapan peserta didik melakukan kegiatan belajar. Tugas yang diberikan oleh guru dapat dikerjakan dimanapun seperti didalam kelas, perpustakaan, rumah ataupun tempat lainnya. Metode ini dapat diterapkan sebagai jalan pintas untuk mempelajari materi dengan bobot yang cukup banyaksedangkan waktu yang diberikan cukup singkat. ${ }^{12}$

Menurut Sudjana tugas dan resitasi dapat merangsang anak untuk lebih aktif belajar secara individual ataupun kelompok, maka dari itu dalam metode resitasi ini pemberian tugas bisa dilakukan secara individual atau kelompok. ${ }^{13}$

Menurut pendapat lain metode resitasi adalah metode pembelajaran dengan panyijian dimana guru memberikan tugas kepada siswa dan siswa dapat mengerjakannya dikelas, halaman sekolah, bengkel, labolatorium, perpustakaan dan lain-lain. Metode ini dapat diterapkan karena dirasa waktu belajar disekolah sangat singkat sedangkan materi pelajaran yang cukup banyak, agar materi pelajaran dapat diselesaikan sesuai dengan ketentuannya maka metode ini dapaat digunakan untuk mengejar waktu tersebut.

Metode resitasi ini tidaklah sama dengan pemberian pekerjaan rumah, cakupan metode resitasi lebih luas. Metode resitasi merangsang siswa untuk lebih aktif secara individu ataupun kelompok. Resitasi dapat dilakukan dimana saja baik dikelas, lapanga, perpustakaan dan lain-lain. Tugas yang diberikan bermacam-macam tergantung dengan tujuan yang ingin dicapai misalnya tugas menliti, menyusun laporan (tertulis atau lisan). ${ }^{14}$ Pemberian tugas tidak untuk memberatkan atau

${ }_{11}$ Ali mudlofir dan evi fatimatur rusydiyah, Desain Pembelajran Inovatif, (Jakarta: PT Raja Grafindo 2017), 118.

12 Ali Mudlofir dan Evi Fatimatur Rusydiyah, "Desain Pembelajran Inovatif," Jakarta : PT Raja Grafindo, 2017), 118.

${ }_{13}$ Nana Sudjana, Dasar-dasar Proses Belajar Mengajar, (Bandung: Sinar Baru 1989). 81.

${ }^{14}$ Syaiful Bahri Djmarah dan Aswan zain, Strategi Belajar Mengajar, (Jakarta: PT Rineka Cipta 2014), 85. 
mempersulit siswa tetapi untuk memperjelas, memperkaya, dan memperdalam bahan ajar yang diberikan dikelas. Maka dari itu, pemberian tugas harus di sesuaikan dengan bahan ajar karena ada perbedaan tujuan pembelajaran disetiap materi.

Metode konvensional adalah metode yang sudah sering digunakan dan di dominasi oleh guru. Pembelajaran yang menggunakan metode tradisional tidak ada saling ketergantungan diantara anggota kelompok, seringkali tiap individu tidak bertanggung jawab dalam menyelesaikan tugas, terlalu bersifat homogen dengan keanggotaannya. Anggota kelompok hanya belajar sendiri, terlalu terfokus pada penyelesaian tugas, metode konvensional biasanya dikenal dengan metode tradisional dan terpusat pada guru. ${ }^{15}$

b. Langkah-langkah menggunakan metode tugas atau resitasi: ${ }^{16}$

1) Fase Pemberian Tugas

Dalam fase ini guru dalam memberikan tugas harus memperhatikan beberapa hal seperti mengidentifikasi tujuan yang ingin dicapai, pemberian tugas yang jelas dan tepat agar siswa mengerti apa yang harus dilakukan, dalam memberikan tugas guru juga harus memperhatikan kemampuan siswa, ada petunjuk atau sumber yang dapat membantu pekerjaan siswa, menyediakan waktu yang cukup untuk mengerjakan tugas.

2) Langkah Pelaksanaan Tugas

Dalam fase ini guru senantiasa memberikan bimbingan dan pengawasan serta mendorong siswa agar mau belajar dan diusahakan tugas yang diberikan dikerjakan sendiri oleh siswa juga dianjurkan untuk mencatat hasil-hasil yang ia dapatkan

3) Fase Pertanggungjawaban Tugas

Hal yang perlu diperhatikan adalah:

a) Laporan siswa baik lisan/tertulis dari apa yang telah dikerjakan.

b) Ada tanya jawab dan diskusi.

c) Penilaian hasil pekerjaan siswa baik dengan tes atau nontes atau cara lainnya.

d) Fase mempertanggungjawabkan tugas inilah yang disebut resitasi.

4) Metode pemberian tugas memiliki beberapa kelebihan dan kekuranagn yakni sebagai berikut $:^{17}$

15 I Wayan Laba, Skripsi,"Pengaruh Metode Resitasi Tugas Dan Motivasi Berprestasi Terhadap Hasil Belajar Matematika Di SMA Negeri 1 Manggis." Jurnal Ilmiah Pendidikan dan Pembelajaran Ganesha, vol. 1, no. 1, (2011): 3.

16 Direktorat Tenaga Kependidikan Direktorat Jenderal Peningkatan Mutu Pendidik Dan Tenaga Kependidikan Departemen Pendidikan Nasional 2008, Strategi pembelajaran dan pemilibannya, 25. 
Kelebihan metode pemberian tugas

(1) Merangsang siswa untuk lebih aktif.

(2) Siswa dapat berkembang tanpa ada pengawasan guru

(3) Dapat melatih rasa tanggung jawab siswa

(4) Siswa lebih kreatif.

Kekurangannya

(1) Sulit untuk mengontrol hasil kerja siswa, dikerjakan sendiri atau menyontek.

(2) Jika tugas yang diberikan adalah tugas kelompok, maka hanya sebagian siswa saja yang mengerjakan tugas.

(3) Sulit untuk memberikan tugas yang sesuai dengan kemampuan siswa.

(4) Terlalu monoton.

Menurut zakiya drajat dalam Briston Bernardus Manullang pemberian tugas dalam dilakukan beberapa hal yaitu: a) murid diberikan tugas untuk mempelajari dari buku atau yang lainnya baik secara individu atau kelompok dan diberikan jangka waktu dalam mengerjakannya, kemudian murid harus mempertanggung jawabkannya. b) murid diberi tugas untuk melakukan sesuai tujuan pembelajaran yang bertujuan untuk melatih kecakapan dan motorik. c) murid diberi tugas untuk mengatasi masalah dengan cara mencoba untuk mengucapkannya ini bertujuan agar murid mampu berfikir secara logis dalam memecahkan masalah. d) murid diberi tugas bersifat proyek yang bertujuan agar murid terbiasa dengan tanggung jawab. ${ }^{18}$

Dalam metode resitasi ini ada beberapa syarat yang perlu diketahui oleh pendidik dan peserta didik diantaranya: a) tugas yang diberikan harus berkaitan dengan pelajaran yang telah diajarkan sehingga siswa mampu mengerjakan tugas dengan menghubungkan dengan pelajaran. b) guru harus melihat kondisi siswa sebelum memberikan tugas. c) guru memberikan arahan agar tugas ini dikerjakan secara individu. d) peserta didik harus benar-benar faham dengan tugas yang diberikan oleh guru.

Mengajar adalah tempat seseorang guru untuk berkreasi, menciptakan seni. Banyak hal yang dituntut pada seorang guru, tugas guru tidak hanya mengajar atau mentransfer ilmunya saja tapi juga sebisa mungkin dapat memberikan motivasi kepada peserta didiknya. Motivasi

17 Adiatman, Skripsi, "Efektifitas Penerapan Metode Pemberian Tugas (Resitasi) Terhadap Hasil Belajar Siswa Dalam Mata Pelajaran Biologi Kelas Xi Ipa Sma Negeri 1 Sungguminasa Kabupaten Gowa," (Universitas Islam Negeri Alauddin Makassar, 2011), 16-17.

18 Briston Bernardus Manullang, Skripsi, "Pengaruh Penggunaan Metode Resitasi Terhadap Prestasi Belajar Siswa Jurusan Teknik Bangunan Mata Pelajaran Ilmu Bangunan Di Kelas Xa Program Keahlian Teknik Konstruksi Batu Beton Di Smk N2 Pengasih Kulon Progo," (Universitas Negeri Yogyakarta, 2014), 22. 
juga tak kalah penting dalam faktor penunjang dalam keberhasilan tercapainya tujuan pembelajaran. Jika bahan merupakan alat untuk mencapai tujuan maka metode adalah cara mewujudkannya dengan tindakan belajar mengajar, akan tetapi dalam fungsinya metode juga merupakan alat untuk mencapai tujuan pembelajaran tanpa adanya metode kegiatan belajar mengajar tidak akan bisa terlaksana. ${ }^{19}$ Dan juga salah satu komponen penting yang menjadikan proses pembelajaran menjadi lancar dan kondusifnya peserta didik, lingkungan belajar serta sarana dan prasarana yang memadai. ${ }^{20}$

Pembelajaran pada dasarnya adalah proses interaksi antara pendidik dan peserta didik dengan berbagai langkah demi mencapai tujuan pembelajaran proses pembelajaran dalam pendidikan Islam harus memperhatikan perbedaan individu peserta didik serta menghormati harkat, martabat dan kebebasan kan berpikir mengeluarkan pendapat dan menetapkan pendiriannya. ${ }^{21}$ Sebagai seorang guru tentu saja senantiasa ingin meningkatkan diri, untuk meningkatkan kualitas mengajar, serta menyampaikan bahan pengajaran kepada siswa sehingga mudah dipahami. Selain itu guru juga ingin membuat proses pengajaran menjadi fungsional, ini berarti seorang guru harus menguasai metode mengajar. Dalam didaktik khusus, yang di dalamnya terdapat beberapa teori tentang metode mengajar. ${ }^{22}$

Secara harfiah metode memiliki arti cara, dalam konteks umum metode bisa diartikan sebagai cara atau prosedur untuk mencapai tujuan tertentu. ${ }^{23}$ Metode adalah jalan yang dilalui untuk mencapai tujuan

\footnotetext{
${ }^{19}$ Briston Bernardus Manullang, Skripsi, "Pengaruh Penggunaan Metode Resitasi Terhadap Prestasi Belajar Siswa Jurusan Teknik Bangunan Mata Pelajaran Ilmu Bangunan Di Kelas Xa Program Keahlian Teknik Konstruksi Batu Beton Di Smk N 2 Pengasih Kulon progo", (Universitas Negeri Yogyakarta, 2014), 10.

${ }^{20}$ Ahmad Ma’ruf, "Kontemplasi Pendidikan Islam Berbasis Pemberdayaan Ekonomi(Di Pesantren Sunan Kalijogo Jabung Malang), AL MURABBI:Jurnal Pendidikan Agama Islam, no. 1 (Desember 2019): 19, diakses pada 6 Juli 2020.
}

${ }^{21}$ M. Anang Sholikhudin dan Nur Kholis, "Komparasi Model Pembelajaran Pendidikan Agama Islam Di Smpn 01 Rembang Dan Smp Darut Tauhid Bangil" al-Murabbi (Volume 1, Nomor 2 (2016) : 360, diakses pada 6 Juli 2020,

\section{https://jurnal.yudharta.ac.id/v2/index.php/pai/article/view/403/307}

22 Siti Maesaroh, "Peranan Metode Pembelajaran Terhadap Minat Dan Prestasi Belajar Pendidikan Agama Islam,” Jurnal Kependidikan, Vol. 1(Nopember 2013): 154-155.

${ }^{23}$ Faturahman dan Sutikno, Strategi Belajar Mengajar, (Bandung: PT. Refika Aditama, 2014), 55. 
tertentu. ${ }^{24}$ Metode bisa berarti urutan strategi dalam melaksanakan suatu pekerjaan, apabila di singkronkan dengan pendidikan maka cara tersebut harus terealisasikan dalam pendidikan dalam rangka mengembangkan aspek Kognitif, Afektif dan Pskomotorik agar peserta didik mudah menerima materi ajar. ${ }^{25}$ Menurut Djamarah metode adalah cara yang memiliki nilai strategi dalam kegiatan belajar mengajar dan yang dimaksud nilai strategi adalah metode yang dapat berpengaruh dalam kegiatan belajar mengajar. ${ }^{26}$ Metode mengajar juga sebagai alat dalam pencapaian tujuan pembelajaran maka perlu adanya tentang pengetahuan itu sendiri, dalam merumuskan tujuan harus sejelas-jelasnya karena itu adalah merupakan bagian syarat yang paling penting sebelum seorang pendidik menentukan dan memilih metode mengajar yang tepat. ${ }^{27}$

\section{Metode Penelitian}

Penelitian ini menggunakan pendekatan kuantitatif. Pendekatan kuantitatif yaitu suatu penelitian yang pada dasarnya menggunakan pendekatan deduktif-induktif. ${ }^{28}$ Pendekatan ini berangkat dari suatu kerangka teori, gagasan para ahli, maupun pemahaman peneliti berdasarkan pengalamannya, kemudian dikembangkan melalui permasalahan-permasalahan dan pemecahan-pemecahannya yang diajukan untuk memperoleh pembenaran (verifikasi) atau penolakan dalam bentuk dukungan data empiris di lapangan. ${ }^{29}$

Adapun tipe penelitian eksperimen yang peneliti gunakan dalam penelitian ini adalah pre-experimental, dengan menggunakan the one group pretest-posttest design. Pre-experimental yaitu penelitian eksperimen yang pada prinsipnya hanya menggunakan satu kelompok, hal ini berarti dalam tipe penelitian tidak ada kelompok kontrol. ${ }^{30}$ Sedangkan the one group pretest-posttes tdesign merupakan desain penelitian yang terdapat Pre Test sebelum diberi perlakuan dan post test

\footnotetext{
${ }^{24}$ Ali Mohtarom dan Wiwin Qomariyah, "Implementasi Metode Apel Dalam Menghafal Juz 'Amma Guna Meningkatkan Daya Ingat Santri Madin Childern” al-Murabbi, (Volume 1, Nomor 1, 2016): 33, diakses pada 6 Juli 2020, https://jurnal.yudharta.ac.id/v2/index.php/pai/article/view/386

${ }^{25}$ Ramayluis, Metodelogi Pendidikan Agama Islam, (Jakarta: Kalam Mulia, 2012), 4.

${ }^{26}$ Faturahman dan Sutikno, Strategi Belajar Mengajar, (Bandung: PT. Refika Aditama, 2014), 11.

${ }^{27}$ Muhammada dan Chicha Latifatul Mahgfiroh, "Implementasi Metode Pembelajaran Aquila Dalam Meningkatkan Pembelajaran Pai Di Smpn 1 Purwosari” al-Murabbi, (Volume 1, Nomor 1, 2016):95, diakses pada 6 juli 2020, https://jurnal.yudharta.ac.id/v2/index.php/pai/article/view/389/294

${ }_{28}$ Ahmad Tanzeh, Metodologi Penelitian Praktis, (Yogyakarta: Teras, 2011), 10.

${ }^{29}$ Tim Laboratorium Jurusan, Pedoman Penyusunan Skripsi IAIN Tulungagung, (Tulungagung, 2015), 13.

${ }^{30}$ A. Muri Yusuf, Metode Penelitian, (Jakarta: PT. Fajar Interpratama Mandiri, 2017), 78.
} 
setelah diberi perlakuan. Adapun rancangan penelitiannya sebagaimana tabel di bawah ini:

One Group Pre Test Post test Design

\begin{tabular}{|l|l|l|}
\hline Pre Test & Perlakuan & Post test \\
\hline O1 & $\mathrm{X}$ & $\mathrm{O} 2$ \\
\hline
\end{tabular}

Keterangan:

$\mathrm{O} 1$ = nilai Pre Test (sebelum diberi perlakuan)

$\mathrm{X}=$ perlakuan menggunakan metode resitasi

$\mathrm{O} 2$ = nilai post test (setelah diberi perlakuan)

Melalui pendekatan ini peneliti dapat menguji hipotesis dengan metode kuantitatif sekaligus menggambarkan hasil penelitian dengan cara dipaparkan dalam bentuk uraian-uraian yang menunjukkan bagaimana implemntasi pembelajaran pendidikan aswaja nahdlatul ulama dengan menggunakan metode resitasi dan pengaruhnya terhadap hasil belajar siswa.

\section{Hasil dan Pembahasan}

Berikut peneliti memaparkan hasil belajar siswa kelas IV Madrasah Diniyah Shobibur Rohmat yang telah dilakukan pada waktu proses kegiatan pembelajaran:

1. Kondisi Awal (Pre Test)

Hasil belajar pada mata pelajaran Pendidikan Aswaja Nahdlatul Ulama kelas IV dapat diketahui dari nilai tes siswa. Adapun deskripsi hasil belajar awal atau pretest dapat dilihat pada tabel berikut ini:

Hasil Pre-Test

\begin{tabular}{|c|l|c|}
\hline NO & \multicolumn{1}{|c|}{ NAMA } & Hasil Pre-Test \\
\hline 1 & AINUN NISA & 70 \\
\hline 2 & ARDIANSYAH & 65 \\
\hline 3 & ARIF WIYOYON & 60 \\
\hline 4 & CHAURELYA ADINDA & 65 \\
\hline 5 & DENY JULIANTO & 60 \\
\hline 6 & DIDIK & 50 \\
\hline 7 & IMADATUS SHOLIKHA & 75 \\
\hline
\end{tabular}




\begin{tabular}{|c|l|c|}
\hline 8 & JEFRI SETIAWAN & 60 \\
\hline 9 & MIFTAKHUL SAFITRI & 70 \\
\hline 10 & NADYA SINTA & 80 \\
\hline 11 & NANDA SAPUTRA & 60 \\
\hline 12 & NELI AGUSTINA & 65 \\
\hline 13 & NURDIANSYAH RAMADANI & 55 \\
\hline 14 & RIZKY HIDAYATULLOH & 50 \\
\hline 15 & SANDRA & 60 \\
\hline 16 & SLAMET DWI SUTANTO & 70 \\
\hline 17 & SUHENDRA KURNIAWAN & 60 \\
\hline 18 & TOHA LUTFI AZIZ & 55 \\
\hline 19 & WENDI DEWI SALSABILA & 75 \\
\hline \multicolumn{2}{|c|}{ Jumlah } & 1205 \\
\hline \multicolumn{2}{|l|}{ Nilai Minimum } & 50 \\
\hline \multicolumn{2}{|l|}{ Nilai Maksimum } & 63,42 \\
\hline \multicolumn{2}{|l|}{ Rata-rata } \\
\hline
\end{tabular}

Dari tabel diatas bisa kita lihat hasil tes awal atau pretest yang diperoleh siswa kelas IV Madrasah Diniyah Shobibor Rohmat sebelum diterapkannya metode resitasi dapat dilihat bahwa nilai rata-rata hasil belajar Pendidikan Aswaja Nahdlatul Ulama adalah sebesar 63,42 dengan nilai minimum 50 dan maksimum 80 .

2. Kondisi Akhir (Post Test)

Hasil belajar pendidikan Aswaja Nahdlatul Ulama kembali diukur melalui tes setelah pelaksanaan pembelajaran dengan menggunakan metode resitasi Adapun deskripsi hasil belajar akhir atau postes dapat dilihat pada tabel berikut ini:

Hasil Post-Test

\begin{tabular}{|c|c|c|}
\hline NO & \multicolumn{1}{|c|}{ Nama } & Hasil Post-Test \\
\hline 1 & AINUN NISA & 85 \\
\hline
\end{tabular}




\begin{tabular}{|c|l|c|}
\hline 2 & ARDIANSYAH & 60 \\
\hline 3 & ARIF WIYOYON & 70 \\
\hline 4 & CHAURELYA ADINDA & 75 \\
\hline 5 & DENY JULIANTO & 70 \\
\hline 6 & DIDIK & 60 \\
\hline 7 & IMADATUS SHOLIKHA & 100 \\
\hline 8 & JEFRI SETIAWAN & 75 \\
\hline 9 & MIFTAKHUL SAFITRI & 80 \\
\hline 10 & NADYA SINTA & 100 \\
\hline 11 & NANDA SAPUTRA & 75 \\
\hline 12 & NELI AGUSTINA & 75 \\
\hline 13 & NURDIANSYAH RAMADANI & 70 \\
\hline 14 & RIZKY HIDAYATULLOH & 65 \\
\hline 15 & SANDRA & 65 \\
\hline 16 & SLAMET DWI SUTANTO & 85 \\
\hline 17 & SUHENDRA KURNIAWAN & 70 \\
\hline 18 & TOHA LUTFI AZIZ & 70 \\
\hline 19 & WENDI DEWI SALSABILA & 95 \\
\hline Jumlah & 1445 \\
\hline Nilai Minimum & 60 \\
\hline Nilai Maksimum & 76,05 \\
\hline Rata-rata & \\
\hline
\end{tabular}

Dari tabel diatas dapat dilihat bahwa nilai rata-rata hasil belajar Pendidikan Aswaja Nahdlatul Ulama setelah menggunakan metode resitasi adalah sebesar 76,05 dengan nilai minimum 60 dan maksimum 100.

Selanjutnya dilakukan analisis data Analisis data adalah proses mencari dan menyusun secara sistematis data yang diperoleh dari hasil wawancara, catatan lapangan, dan dokumentasi, dengan cara 
mengorganisasikan data ke dalam kategori, menjabarkan ke dalam unitunit, melakukan sintesa, menyusun ke dalam pola, memilih mana yang penting dan yang akan dipelajari, dan membuat kesimpulan sehingga mudah dipahami oleh diri sendiri dan orang lain. ${ }^{31}$ Analisis data proses mencari data dan menyusun secara sistematis hasil data yang diperoleh oleh peneliti. ${ }^{32}$ Dan dalam penelitian ini peneliti dalam menganalisis data menggunakan aplikasi SPSS versi 24 dan mendapatkan hasil sebagai berikut

\section{a. Paparan Data Perhitungan SPSS}

\begin{tabular}{|l|l|l|r|r|c|}
\hline \multicolumn{7}{|c|}{ Paired Samples Statistics } \\
\hline \multirow{2}{*}{} & Mean & N & Std. Deviation & $\begin{array}{c}\text { Std. Error } \\
\text { Mean }\end{array}$ \\
\hline Pair 1 & pre_test & 63,4211 & 19 & 8,34210 & 1,91381 \\
\cline { 2 - 7 } & post_test & 76,0526 & 19 & 12,08522 & 2,77254 \\
\hline
\end{tabular}

Pada hasil out put SPSS ini diperlihatkan hasil ringkasan statistik deskriptif dari kedua data dari hasil nilai belajar siswa sebelum menggunakan metode resitasi (pre test) dan hasil nilai belajar siswa sesudah menggunakan metode resitasi (post test). Dari data tersebut dijelaskan mean (nilai rata-rata) Pre Test yaitu 63,42 dan untuk nilai mean post test yaitu 76, 05. Dengan nilai standar deviasi Pre Test sebesar 8,34dan nilai standar deviasi post test sebesar 12,08.

\begin{tabular}{|c|c|c|c|c|c|c|c|}
\hline \multicolumn{8}{|c|}{ Paired Samples Test } \\
\hline \multicolumn{5}{|c|}{ Paired Differences } & \multirow[b]{3}{*}{$\mathrm{t}$} & \multirow[b]{3}{*}{ Df } & \multirow{3}{*}{$\begin{array}{l}\text { Sig. } \\
(2- \\
\text { tailed })\end{array}$} \\
\hline \multirow{2}{*}{$\begin{array}{c}\text { Mea } \\
n\end{array}$} & \multirow{2}{*}{$\begin{array}{c}\text { Std. } \\
\text { Deviati } \\
\text { on }\end{array}$} & \multirow{2}{*}{$\begin{array}{l}\text { Std. } \\
\text { Error } \\
\text { Mean }\end{array}$} & \multicolumn{2}{|c|}{$\begin{array}{c}95 \% \\
\text { Confidence } \\
\text { Interval of the } \\
\text { Difference }\end{array}$} & & & \\
\hline & & & Lower & Upper & & & \\
\hline
\end{tabular}

${ }^{31}$ Sugiyono, Metode Penelitian Kuantitatif, Kualitatif dan R\&D, (Bandung : ALFABETA, 2008), 244.

32 Ahmad Ma'ruf, "Kontemplasi Pendidikan Islam Berbasis Pemberdayaan Ekonomi(Di

Pesantren Sunan Kalijogo Jabung Malang), AL MURABBI: Jurnal Pendidikan Agama

Islam, no. 1 (Desember 2019): 23, diakses pada 6 Juli 2020. 


\begin{tabular}{|l|l|r|r|r|r|r|r|r|r|}
\hline Pa & pre_test - & - & 6,3176 & 1,4493 & - & - & - & 18 &, 000 \\
ir 1 & post_test & 12,6 & 2 & 6 & 15,676 & 9,5865 & 8,71 & & \\
& & 3158 & & & 57 & 9 & 5 & & \\
\hline
\end{tabular}

Dalam pengambilan keputusan diterima atau ditolaknya hipotesis adalah sebagai berikut:

1. Apabila nilai probabilitas signifikansi < a $(0,05)$, maka Ho ditolak dan Ha diterima.

2. Apabila nilai probabilitas signifikansi $>$ a $(0,05)$, maka Ho diterima dan Ha ditolak.

Dari hasil uji paired sample test didapat hasil sig (2-tailed) yaitu 0,000 dan diketahui bahwa nilai signifikansi (2-tailed) sebesar 0,000< 0,05 . Maka hasilnya adalah Ho ditolak dan Ha diterima. Jadi dapat disimpulkan bahwa terdapat pengaruh yang signifikan antara hasil belajar pre test dan post test. Sehingga dari hasil ini dapat kita simpulkan bahwa melalui penggunaan metode resitasi terhadap pembelajaran Aswaja Nahdlatul Ulama terdapat pengaruh terhadap hasil belajar siswa kelas IV Madrasah Diniyah Shobibur Rohmat.

b. Paparan data hasil perhitungan t Tabel

Diketahui nilai t hitung setelah perhitungan menggunakan SPSS adalah -8,715 dan degree of freedom (df) adalah 18 maka dapat nilai $t$ tabel dapat dilihat sebagai berikut :

Titik Persentase Distribusi t $(\mathrm{df}=1-40)$

\begin{tabular}{|c|c|c|c|c|c|c|c|}
\hline $\mathbf{P r}$ & $\mathbf{0 . 2 5}$ & $\mathbf{0 . 1 0}$ & $\mathbf{0 . 0 5}$ & $\mathbf{0 . 0 2 5}$ & $\mathbf{0 . 0 1}$ & $\mathbf{0 . 0 0 5}$ & $\mathbf{0 . 0 0 1}$ \\
\hline $\mathbf{d f}$ & $\mathbf{0 . 5 0}$ & $\mathbf{0 . 2 0}$ & $\mathbf{0 . 1 0}$ & $\mathbf{0 . 0 5 0}$ & $\mathbf{0 . 0 2}$ & $\mathbf{0 . 0 1 0}$ & $\mathbf{0 . 0 0 2}$ \\
\hline $\mathbf{1}$ & 1.00000 & 3.07768 & 6.31375 & $\begin{array}{c}12.7062 \\
0\end{array}$ & $\begin{array}{c}31.8205 \\
\mathbf{2}\end{array}$ & $\begin{array}{c}63.6567 \\
4\end{array}$ & $\begin{array}{c}318.308 \\
84\end{array}$ \\
\hline $\mathbf{2}$ & 0.81650 & 1.88562 & 2.91999 & 4.30265 & 6.96456 & 9.92484 & $\begin{array}{c}22.3271 \\
\mathbf{2}\end{array}$ \\
\hline $\mathbf{3}$ & 0.76489 & 1.63774 & 2.35336 & 3.18245 & 4.54070 & 5.84091 & $\begin{array}{c}10.2145 \\
3\end{array}$ \\
\hline $\mathbf{4}$ & 0.74070 & 1.53321 & 2.13185 & 2.77645 & 3.74695 & 4.60409 & 7.17318 \\
\hline $\mathbf{5}$ & 0.72669 & 1.47588 & 2.01505 & 2.57058 & 3.36493 & 4.03214 & 5.89343 \\
\hline $\mathbf{6}$ & 0.71756 & 1.43976 & 1.94318 & 2.44691 & 3.14267 & 3.70743 & 5.20763 \\
\hline $\mathbf{7}$ & 0.71114 & 1.41492 & 1.89458 & 2.36462 & 2.99795 & 3.49948 & 4.78529 \\
\hline $\mathbf{8}$ & 0.70639 & 1.39682 & 1.85955 & 2.30600 & 2.89646 & 3.35539 & 4.50079 \\
\hline $\mathbf{9}$ & 0.70272 & 1.38303 & 1.83311 & 2.26216 & 2.82144 & 3.24984 & 4.29681 \\
\hline $\mathbf{1 0}$ & 0.69981 & 1.37218 & 1.81246 & 2.22814 & 2.76377 & 3.16927 & 4.14370 \\
\hline $\mathbf{1 1}$ & 0.69745 & 1.36343 & 1.79588 & 2.20099 & 2.71808 & 3.10581 & 4.02470 \\
\hline
\end{tabular}




\begin{tabular}{|l|l|l|l|l|l|l|l|}
\hline $\mathbf{1 2}$ & 0.69548 & 1.35622 & 1.78229 & 2.17881 & 2.68100 & 3.05454 & 3.92963 \\
\hline $\mathbf{1 3}$ & 0.69383 & 1.35017 & 1.77093 & 2.16037 & 2.65031 & 3.01228 & 3.85198 \\
\hline $\mathbf{1 4}$ & 0.69242 & 1.34503 & 1.76131 & 2.14479 & 2.62449 & 2.97684 & 3.78739 \\
\hline $\mathbf{1 5}$ & 0.69120 & 1.34061 & 1.75305 & 2.13145 & 2.60248 & 2.94671 & 3.73283 \\
\hline $\mathbf{1 6}$ & 0.69013 & 1.33676 & 1.74588 & 2.11991 & 2.58349 & 2.92078 & 3.68615 \\
\hline $\mathbf{1 7}$ & 0.68920 & 1.33338 & 1.73961 & 2.10982 & 2.56693 & 2.89823 & 3.64577 \\
\hline $\mathbf{1 8}$ & 0.68836 & 1.33039 & 1.73406 & 2.10092 & 2.55238 & 2.87844 & 3.61048 \\
\hline $\mathbf{1 9}$ & 0.68762 & 1.32773 & 1.72913 & 2.09302 & 2.53948 & 2.86093 & 3.57940 \\
\hline $\mathbf{2 0}$ & 0.68695 & 1.32534 & 1.72472 & 2.08596 & 2.52798 & 2.84534 & 3.55181 \\
\hline $\mathbf{2 1}$ & 0.68635 & 1.32319 & 1.72074 & 2.07961 & 2.51765 & 2.83136 & 3.52715 \\
\hline $\mathbf{2 2}$ & 0.68581 & 1.32124 & 1.71714 & 2.07387 & 2.50832 & 2.81876 & 3.50499 \\
\hline $\mathbf{2 3}$ & 0.68531 & 1.31946 & 1.71387 & 2.06866 & 2.49987 & 2.80734 & 3.48496 \\
\hline $\mathbf{2 4}$ & 0.68485 & 1.31784 & 1.71088 & 2.06390 & 2.49216 & 2.79694 & 3.46678 \\
\hline $\mathbf{2 5}$ & 0.68443 & 1.31635 & 1.70814 & 2.05954 & 2.48511 & 2.78744 & 3.45019 \\
\hline $\mathbf{2 6}$ & 0.68404 & 1.31497 & 1.70562 & 2.05553 & 2.47863 & 2.77871 & 3.43500 \\
\hline $\mathbf{2 7}$ & 0.68368 & 1.31370 & 1.70329 & 2.05183 & 2.47266 & 2.77068 & 3.42103 \\
\hline $\mathbf{2 8}$ & 0.68335 & 1.31253 & 1.70113 & 2.04841 & 2.46714 & 2.76326 & 3.40816 \\
\hline $\mathbf{2 9}$ & 0.68304 & 1.31143 & 1.69913 & 2.04523 & 2.46202 & 2.75639 & 3.39624 \\
\hline $\mathbf{3 0}$ & 0.68276 & 1.31042 & 1.69726 & 2.04227 & 2.45726 & 2.75000 & 3.38518 \\
\hline $\mathbf{3 1}$ & 0.68249 & 1.30946 & 1.69552 & 2.03951 & 2.45282 & 2.74404 & 3.37490 \\
\hline $\mathbf{3 2}$ & 0.68223 & 1.30857 & 1.69389 & 2.03693 & 2.44868 & 2.73848 & 3.36531 \\
\hline $\mathbf{3 3}$ & 0.68200 & 1.30774 & 1.69236 & 2.03452 & 2.44479 & 2.73328 & 3.35634 \\
\hline $\mathbf{3 4}$ & 0.68177 & 1.30695 & 1.69092 & 2.03224 & 2.44115 & 2.72839 & 3.34793 \\
\hline $\mathbf{3 5}$ & 0.68156 & 1.30621 & 1.68957 & 2.03011 & 2.43772 & 2.72381 & 3.34005 \\
\hline $\mathbf{3 6}$ & 0.68137 & 1.30551 & 1.68830 & 2.02809 & 2.43449 & 2.71948 & 3.33262 \\
\hline $\mathbf{3 7}$ & 0.68118 & 1.30485 & 1.68709 & 2.02619 & 2.43145 & 2.71541 & 3.32563 \\
\hline $\mathbf{3 8}$ & 0.68100 & 1.30423 & 1.68595 & 2.02439 & 2.42857 & 2.71156 & 3.31903 \\
\hline $\mathbf{3 9}$ & 0.68083 & 1.30364 & 1.68488 & 2.02269 & 2.42584 & 2.70791 & 3.31279 \\
\hline $\mathbf{4 0}$ & 0.68067 & 1.30308 & 1.68385 & 2.02108 & 2.42326 & 2.70446 & 3.30688 \\
\hline & & & & & & & \\
\hline
\end{tabular}

Berdasarkan dari tabel diatas maka nilai t tabel diperoleh sebesar 2,10092 dan derajat kebebasan (df) dari sampel adalah $\mathrm{df}=18$, probabilitas atau taraf signifikansi yang dipakai dalam penelitian ini adalah 0,05 dengan uji dua arah maka diperoleh nilai t-tabel sebesar 
2,10092. Selanjutnya nilai t-hitung hasil perhitungan SPSS adalah sebesar -8,715 karena t-hitung bernilai minus maka perbandingan ttabel harus bernilai minus yang artinya hasil dari t-tabel menjadi 2,10092 .

Dengan demikian jika digunakan pengambilan keputusan dengan membandingkan nilai t-hitung terhadap nilai t-tabel adalah sebagai berikut :

a) Apabila nilai t-hitung $>$ t-tabel maka Ha diterima dan $\mathrm{HO}$ ditolak.

b) Apabila nilai t-hitung < t-tabel maka $\mathrm{HO}$ diterima dan Ha ditolak.

Berdasarkan data diatas maka dari penelitian ini bisa diambil keputusan bahwa Ha diterima artinya Ada pengaruh yang signifikan antara penerapan metode resitasi terhadap prestasi hasil belajar pendidikan aswaja nahdlatul ulama kelas IV Madrasah Diniyah Shobibur Rohmat Ketuwon Sumberrejo.

\section{E. Kesimpulan}

Berdasarkan paparan data di atas menyimpulkan bahwa Metode Resitasi yang dilakukan oleh peneliti cukup efektif digunakan. Hal ini dibuktikan dengan eksperimen yang dilakukan oleh peneliti pada kelas IV Madrasah Diniyah Shobibur Rohmat.

1. Nilai hasil belajar siswa terdapat perbedaan yang signifikan antara sebelum mengikuti pembelajaran metode resitasi dan sesudah mengikuti pembelajaran resitasi. Perbedaan hasil belajar ini di tunjukkan dengan hasil analisis menggunakan rumus uji $t$ dengan perolehan (Sig.) 0,00 0,05 dari soal yang diujikan kepada siswa dapat diketahui hasil belajar mata pelajaran pendidikan aswaja nahdlatul ulama kelas IV nilai rata-rata yang diperoleh yakni dari 63,42 menjadi 76,05.

2. Berdasarkan hasil analisis uji Paired Sampel T Test diperoleh angka signifikansi 0,00 dimana angka signifikansi lebih kecil dari 0,05 maka hipotesis yang menyatakan ada pengaruh penerapan metode Resitasi terhadap prestasi hasil belajar pendidikan aswaja nahdlatul ulama kelas IV di Madrasah Diniuah Shobibur Rohmat Ketuwon Sumberrejo dan artinya Ha diterima dan Ho ditolak. Yang bisa disimpulkan bahwa Terdapat pengaruh penggunaan metode reswitasi terhadap hasil belajar siswa pada mata pelajaran pendidikan aswaja nahdlatul ulama yang ditunjukkan pada perbedaan rata-rata nilai kelas sebelum menggunakan metode resitasi adalah 63,42 sedangkan sesudah menggunakan metode resitasi hasil belajar siswa mengalami peningkatan dengan nilai rata-rata kelas yaitu 76, 05 .

\section{F. Daftar Pustaka}

A. Muri Yusuf, Metode Penelitian, (Jakarta: PT. Fajar Interpratama Mandiri, 2017). 
Adiatman, Skripsi, "Efektifitas Penerapan Metode Pemberian Tugas (Resitasi) Terhadap Hasil Belajar Siswa Dalam Mata Pelajaran Biologi Kelas Xi Ipa Sma Negeri 1 Sungguminasa Kabupaten Gowa," (Universitas Islam Negeri Alauddin Makassar, 2011).

Ahmad Ma'ruf, "Kontemplasi Pendidikan Islam Berbasis Pemberdayaan Ekonomi(Di Pesantren Sunan Kalijogo Jabung Malang), AL MURABBI:Jurnal Pendidikan Agama Islam, no. 1 (Desember 2019)

Ahmad Tanzeh, Metodologi Penelitian Praktis, (Yogyakarta: Teras, 2011). Ali Mohtarom dan Wiwin Qomariyah, "Implementasi Metode Apel Dalam Menghafal Juz 'Amma Guna Meningkatkan Daya Ingat Santri Madin Childern" al-Murabbi, (Volume 1, Nomor 1, 2016).

Ali mudlofir dan evi fatimatur rusydiyah, Desain Pembelajran Inovatif, (Jakarta: PT Raja Grafindo 2017).

Briston Bernardus Manullang, Skripsi, "Pengaruh Penggunaan Metode Resitasi Terhadap PrestasiBelajar Siswa Jurusan Teknik Bangunan Mata Pelajaran Ilmu Bangunan Di Kelas Xa Program Keahlian Teknik Konstruksi Batu Beton Di Smk N 2 Pengasih Kulon progo", (Universitas Negeri Yogyakarta, 2014).

Direktorat Tenaga Kependidikan Direktorat Jenderal Peningkatan Mutu Pendidik Dan Tenaga Kependidikan Departemen Pendidikan Nasional 2008, Strategi pembelajaran dan pemilihannya.

Faturahman dan Sutikno, Strategi Belajar Mengajar, (Bandung: PT. Refika Aditama, 2014).

Fuat agus santoso, Skripsi, "kreativitas belajarsiswa ditinjau dari lingkungan keluarga dan fasilitas belajar pada siswa kelas VIII SMP N 1 Kartasura tahun ajaran 2013/2014", (universitas muhammadiyah surakarta, 2014).

I Wayan Laba, Skripsi,"Pengaruh Metode Resitasi Tugas Dan Motivasi Berprestasi Terhadap Hasil Belajar Matematika Di SMA Negeri 1 Manggis." Jurnal Ilmiah Pendidikan dan Pembelajaran Ganesha, vol. 1, no. 1, (2011).

M. Anang Sholikhudin dan Nur Kholis, "Komparasi Model Pembelajaran Pendidikan Agama Islam Di Smpn 01 Rembang Dan Smp Darut Tauhid Bangil" al-Murabbi (Volume 1, Nomor 2 (2016).

Muhammad Sholih, Muhammad Farid dan Abdul Karim, Pendidikan Aswaja dan Nahdlatul Ulama (Ma'hadud Tarbiyah wa ta'lim Maarif nahdlatul ulama kabupaten pasuruan, 2014).

Muhammada dan Chicha Latifatul Mahgfiroh, "Implementasi Metode Pembelajaran Aquila Dalam Meningkatkan Pembelajaran Pai Di Smpn 1 Purwosari" al-Murabbi, (Volume 1, Nomor 1, 2016). 
Nana Sudjana, Dasar-dasar Proses Belajar Mengajar, (Bandung: Sinar Baru 1989).

Ramayluis, Metodelogi Pendidikan Agama Islam, (Jakarta: Kalam Mulia, 2012).

Rizka Ramadhanti, Skripsi, "Upaya Meningkatkan Hasil Belajar Siswadengan MengunakanMetode Inquiri Learning Pada Mata Pelajaran Alqur'an Hadits Materi Hukum Bacaan Idgham Bighunnah,Idgham Bilaghunna Dan Ikhfa Di Kelas VIII Di Mts AlIkhlas Pangkalan Susu", (Sekolah Tinggi Agama Islam Jam'iyah Mahmudiyah Tanjung Puralangkat, 2018).

Romi Anshorulloh, Skripsi, "Efektivitas Metode Mnemonika Dalam Meningkatkan Daya Ingat Siswa Dalam Pelajaran Sejarah di MTS Persiapan Negeri Kota Batu" (Universitas Islam Negeri Malang, 2008).

Rosniah, Skripsi, "Meningkatkan daya ingat siswa dalam menghafal Asmaul husna melalui strategi index card Match pada siswa kelas II sekolah dasar Negeri 013 teluk air karimun" (Universitas Islam Negeri Sultan Syarif Kasim Riau, 2013).

Sholih Muhammad, Muhammad Farid dan Abdul Karim, Pendidikan Aswaja dan Nahdlatul Ulama, (Ma'hadud Tarbiyah wa ta'lim Maarif nahdlatul ulama kabupaten pasuruan, 2014).

Siti Choriyah, Skripsi, "Implementasi Pembelajaran Aswaja Untuk Peningkatan Iman Dan Taqwadi Smk Al Falahsalatiga" (Institut Agama Islam Negeri (iain) Salatiga, 2018).

Siti Maesaroh, "Peranan Metode Pembelajaran Terhadap Minat Dan Prestasi Belajar Pendidikan Agama Islam," Jurnal Kependidikan, Vol. 1(Nopember 2013).

Sugiyono, Metode Penelitian Kuantitatif, Kualitatif dan R\&D, (Bandung : ALFABETA, 2008).

Syaiful Bahri Djmarah dan Aswan zain, Strategi Belajar Mengajar, (Jakarta: PT Rineka Cipta 2014).

Tim Laboratorium Jurusan, Pedoman Penyusunan Skripsi IAIN Tulungagung, (Tulungagung, 2015).

Untari Retno Wulan, Skripsi, "efektivitas brain gyn dalam meningkatkan daya ingat jangka pendek pada anak" (Universitas muhammadiyah surakarta, 2010).

Zulkifli, Skripsi, "Meningkatkan Hasil Belajar Siswa Pada Mata Pelajaran Akidah Akhlak Kelas Viii-A Pokok Bahasan Beriman Kepada Kitab Allah Dengan Penerapan Strategi Index Card Match Di Madrasah Tsanawiyah Swasta Nurul Wathan Tahun Ajaran 2013/2014", (Institut Agama Islam Darul Al-Ulum, 2014). 